\title{
Sodelovanje javnosti v postsocialističnih mestih med stagnacijo in napredkom: primer Zagreba in Ljubljane
}

Sodelovanje javnosti pri urbanistični preobrazbi glavnega mesta je pomemben dejavnik, ki ga je treba upoštevati pri presoji kakovosti demokracije v postsocialističnih državah. V članku avtorji obravnavajo procese sodelovanja javnosti pri taki preobrazbi v dveh postsocialističnih glavnih mestih: v Zagrebu in Ljubljani. Predstavljeni so izsledki izbranih študij primerov v obeh mestih (park Tabor in soseska BS $7 \mathrm{v}$ Ljubljani ter Meštrovićev paviljon in park Savica v Zagrebu), poleg tega so izpostavljene podobnosti in razlike, ugotovljene na podlagi njihove primerjave. Izsledki raziskave iz let 2018 in 2019 kažejo dokaj nizko stopnjo sodelovanja javnosti v Zagrebu. V Ljubljani je bila navedena stopnja višja in tudi pravna podlaga zanjo je bila močnejša, opazna pa je bila delna odvisnost od političnih in gospodarskih dejavnikov. V obeh mestih je bilo sodelovanje javnosti v najbolj neposredni obliki pri aktivnostih nevladnih organizacij in civilnih pobud. Komunikacija med prebivalci in mestno upravo je bila slaba, kar ni spodbudno vplivalo na sodelovanje.

Ključne besede: sodelovanje, pobude civilne družbe, primerjalna metoda, Zagreb, Ljubljana 


\section{Uvod}

V Jugoslaviji, katere del sta bili tudi Hrvaška in Slovenija, je bilo prostorsko upravljanje odvisno od družbenopolitičnih razmer in je večinoma temeljilo na planiranju in državnem nadzoru. Socialna, gospodarska in prostorska vprašanja so se obravnavala v okviru sistema družbenega planiranja (Burton idr., 1967) ali društvenega plana, kot so mu rekli na $\mathrm{Hr}$ vaškem (Čaldarović in Kritovac, 1987). V postsocialističnem obdobju država ni več imela tovrstne vloge pri urejanju prostora. Pozornost se je preusmerila na privatizacijo prostora in nepremičnin, ponovno uporabo in prenovo zemljišč ter novo opredelitev vlog načrtovalskih ustanov (Bertaud in Renaud, 1997; Golubchikov, 2004; Dimitrovska Andrews idr., 2007; Hirt, 2012; Sýkora in Stanilov, 2014; Svirčić Gotovac in Kerbler, 2019; Zlatar Gamberožić, 2019). Tržno usmerjeno gospodarstvo je po drugi strani razkrilo pomanjkanje skupnega interesa in vizije $\mathrm{v}$ urbanizmu. $\mathrm{V}$ urbanistični in javni politiki se je uveljavil pristop gospodarskega liberalizma, ki je povzročil (in še naprej povzroča) neenakomeren razvoj mest in gospodarsko neenakost (Offe, 1997; Jaakson, 2000; Nikšič in Sezer, 2017). Posledično so se privlačna mestna območja spremenila v velika gradbišča, dobički od raznih naložb strmo naraščajo, manj privlačna območja pa stagnirajo (Nikšičc, 2014; Patti in Polyak, 2017). Državno tiranijo je nadomestila tržna prevlada (Häussermann in Kapphan, 2004: 26), s katero se je hkrati začela komercializacija mestnega prostora. $V$ razmerah, v katerih so se glavne aktivnosti v mestnem razvoju preusmerile od načrtovanih izboljšav po vsem mestu $k$ dobičkonosnim posegom na ugodnih lokacijah, je treba proučiti vlogo javnosti $\mathrm{v}$ razvojnem procesu. $V$ članku avtorji zato najprej opredelijo sodelovanje javnosti pri urbanističnem odločanju, pri čemer se osredotočijo na dve postsocialistični glavni mesti: Zagreb in Ljubljano.

V postsocialističnih mestih so tržno povpraševanje in zasebni interesi precej pomembnejši od načrtovalskega procesa. Tudi javne naložbe se bolj osredotočajo na tiste dejavnosti in projekte, ki lahko izboljšajo privlačnost mesta $\mathrm{z}$ vidika njegove dobičkonosnosti kot pa splošno kakovost življenja njegovih prebivalcev (Stanilov, 2007; Sykora, 2007; Patti in Polyak, 2017). Prehod iz socializma je bil v urbanizmu zaznamovan $\mathrm{z}$ zanemarjanjem družbene razsežnosti prebivanja $\mathrm{v}$ mestih in tamkajšnjih stanovanj ter strateškega in dolgoročnega urbanističnega načrtovanja. Značilnosti tržnega gospodarstva, ki so se pojavljale od devetdesetih let 20. stoletja (privatizacija, krčenje javnega prostora, globalni finančni sistem), vplivajo na odnose med deležniki v okviru urbanističnega načrtovanja oziroma na njihove vloge in pristojnosti. $\mathrm{V}$ zahodnoevropskih državah se uporabljajo izrazi, kot so visoka stopnja sodelovanja javnosti, visoki pravni standardi in uspešna javno-zasebna partnerstva, države nekdanje Jugoslavije pa se v urbanizmu spopadajo $\mathrm{z}$ omejitvami $\mathrm{v}$ pravnem sistemu in nezadostnim sodelovanjem javnosti pri odločanju. Razloga za dokaj počasen prehod v večini držav nekdanje Jugoslavije sta zagotovo vojna $\mathrm{v}$ devetdesetih letih 20. stoletja ter izoliranost od evropskih in svetovnih smeri razvoja (Beyea idr., 2009). Prehod je bil hitrejši v nekdanjih socialističnih državah, ki so zgodaj začele aktivnosti za pridružitev Evropski uniji, na primer v Sloveniji.

$\mathrm{V}$ primerjavi z drugimi nekdanjimi jugoslovanskimi državami je prehod v Sloveniji potekal dokaj gladko, in sicer zaradi nekaterih prednosti, ki jih je država imela že na začetku: njena vojna za neodvisnost je bila kratka, Evropski uniji pa se je pridružila razmeroma hitro in sprejela njene urbanistične programe. Poleg tega so ji bila kmalu na razpolago sredstva EU in ta sredstva je izkoristila za številne urbanistične projekte, za katere so dale pobudo in jih podprle politične in upravne strukture mest (Zlatar Gamberožić, 2019). Hrvaška je po razglasitvi neodvisnosti in okrepitvi privatizacije $\mathrm{v}$ devetdesetih letih prejšnjega stoletja doživela številne prostorske preobrazbe, $\mathrm{v}$ prostorski razvoj pa se je vključilo tržno gospodarstvo.

$\mathrm{Na}$ Hrvaškem načrtovalski proces v glavnem določajo generalni urbanistični plani na ravni mest, Prostorska razvojna strategija in Urbanistični program Republike Hrvaške ter v primeru Zagreba tudi prostorski načrt mesta Zagreb. V skladu s členi 99-108 generalnega urbanističnega plana mesta Zagreb je treba pri oblikovanju in izvedbi načrtovalskega procesa sprejeti ustrezne urbanistične razvojne načrre, izvesti javne razpise, pripraviti študije in zagotoviti sodelovanje javnosti. Javni razpisi so obvezni za urejanje javnih prostorov (trgov in parkov), generalni plan pa omogoča tudi razvoj mestnih projektov in določa postopek njihove izvedbe. Generalni urbanistični plan se skupaj s spremembami in dopolnitvami pošlje zagrebški mestni skupščini v odobritev. Sodelovanje javnosti je omogočeno v obliki predstavitev, predhodnih razprav o prostorskih načrtih ter javnih posvetovanj o osnutkih prostorskih načrtov in rezultatih javnih razpisov (Grad Zagreb, 2016).

V skladu z Zakonom o urejanju prostora (v nadaljevanju: ZUrep-2; Ur. l. RS, št. 61/17) so za urejanje prostora v Sloveniji pristojne država in občine. Prostorski akti se delijo na strateške in izvedbene akte. Prvi določajo glavno usmeritev prihodnjega razvoja in njegova glavna načela, drugi pa se nanašajo na posamezno območje in so pravno zavezujoči. Pri pripravi strateških načrtov javnost običajno sodeluje prek javnih posvetov, pri pripravi in sprejetju izvedbenih aktov pa je zahtevano njeno aktivnejše sodelovanje - med drugim je treba sodelovanje javnosti že v pripravljalni fazi določiti z načrtom vključevanja javnosti (ZUrep-2, 2017; ESPON, 2018). 


\section{Sodelovanje javnosti kot del urbanističnega načrtovanja}

V skladu z lestvico sodelovanja javnosti, ki jo je vpeljala Sherry R. Arnstein (1969, slika 1), lahko sodelovanje javnosti pri urbanističnem načrtovanju sega vse od manipulacije (najnižja raven) do državljanskega nadzora (najvišja raven). Na najnižjih ravneh (nesodelovanje) ljudje nimajo vpliva na odločanje, hkrati pa se jih z manipulacijo prepriča, da se vse dela v njihovo dobro. Predlagani načrt je najboljši in cilj je doseči javno podporo z obveščanjem javnosti. Na ravni pasivnega ali navideznega sodelovanja je javnost obveščena o urbanističnih projektih, ki potekajo, vendar nima možnosti, da vanje poseže. Šele na stopnji sprave lahko javnost predstavi svoja mnenja, vendar odločevalci niso zavezani, da bi jih tudi upoštevali. $\mathrm{Na}$ stopnji partnerstva in delegiranja moči v tretjem sklopu lestvice je moč porazdeljena med ljudi in odločevalce. Na najvišsi stopnji (državljanski nadzor) lahko prebivalci dajo pobudo za urbanistične projekte in s tem oblikujejo svoje bivalno okolje brez posrednikov in lastnih virov financiranja. Lahko vplivajo na urbanistično politiko in so enakovredni udeleženci v celotnem nacrrtovalskem procesu.

Njeno lestvico so pozneje upoštevali tudi številni drugi avtorji. Anokye (2013) na primer poleg tega obravnava dva pristopa $\mathrm{k}$ sodelovanju, transformativnega in instrumentalnega, pri čemer je možna tudi kombinacija obeh. Transformativni pristop ustreza stopnji nesodelovanja po Arnsteinovi, instrumentalni pa stopnji državljanskega nadzora. Večina sistemov sodelovanja vključuje kombinacijo obeh pristopov, kar pomeni, da je javnost seznanjena s posveti, $v$ njih občasno sodeluje in je obveščena o odločitvah mestne uprave. To pa še ne pomeni, da $\mathrm{v}$ procesu tudi resnično sodeluje in ima moč spreminjanja političnih odločitev. Gre torej za obliko instrumentalnega pristopa, ki vključuje pretok informacij od zgoraj navzdol, akterjem pa ne daje večjega vpliva (Anokye, 2013: 82). Soglasje še vedno ni doseženo, pri tem pa je možen konflikt med vpletenima stranema. Kot navajajo Hordijk idr. (2015), je navedeni pristop povezan z oslabljeno vlogo države in državljanov, pri čemer zadnje opisujejo kot stranke ali potrošnike, ki ne morejo vplivati na odločitve in jih lahko samo upoštevajo, ko so sprejete, saj jih ni več mogoče spremeniti. Transformativni pristop, pri katerem komunikacija poteka od spodaj navzgor, pa vključuje višjo raven sodelovanja, na kateri je javnost aktivneje vključena v odločanje.

\subsection{Sodelovanje javnosti v Zagrebu}

Hrvaška je postala članica Evropske unije leta 2013. Čeprav si prizadeva svoj pravni sistem uskladiti z evropskim in je sprejela že številne dokumente, ki v duhu evropske politike podpirajo

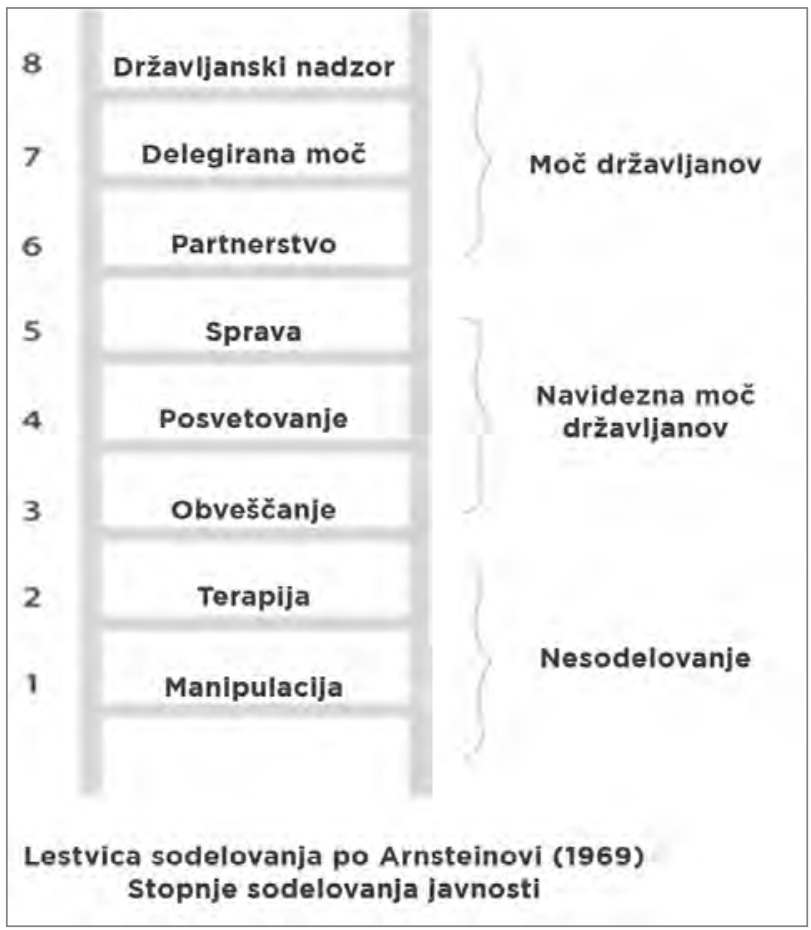

Slika 1: Lestvica sodelovanja javnosti po Sherry R. Arnstein (vir: internet 1)

večjo kohezijo, decentralizacijo, horizontalno upravljanje in večji pomen sodelovanja javnosti pri razvoju mest, ji vse to v praksi ne uspeva najbolje. V skladu s hrvaškim pravom je sodelovanje javnosti omejeno na javni dostop do osnutkov prostorskih načrtov, vendar je ta dostop mogoč samo od 15 do 30 dni. Med tem časom lahko državljani predlagajo spremembe in dopolnitve.

Med javnimi posveti ima javnost pravico sodelovati pri oblikovanju in sprejemanju prostorskih načrtov ter predstaviti svoje predloge ali pripombe. Gre za model sodelovanja od zgoraj navzdol, pri katerem o prostorskih spremembah odloča vlada, upošteva pa se le malo vprašanj, na katera opozorijo prebivalci (npr. glede zasebnega zemljišča na ureditvenem območju). Javnost ima zelo malo vpliva na spremembe, ki jih uvajajo prostorski načrti, in na preureditev (največkrat javnega) prostora. Javni interes je razglašen za pomembnega in dragocenega, vendar je javnost $\mathrm{k}$ sodelovanju pozvana samo uradno ali še to ne in tudi če javnost predstavi svoje predloge, ni nujno, da se ti upoštevajo. Zadnjih nekaj desetletij so mestne oblasti pogosto izvajale projekte, $s$ katerimi se javnost ni strinjala in zaradi katerih se je javni prostor skrčil. Zanimivo je, da se kljub pridružitvi Hrvaške Evropski uniji generalni urbanistični plan mesta Zagreb od leta 2007 ni kaj dosti spreminjal, vseskozi pa se prilagaja tržnim potrebam gospodarskih in političnih akterjev. Sodelovanje med strokovnjaki in politiki ni zadostno, obrambo javnega interesa pa so prevzele nevladne organizacije in razne civilne pobude, ki so se v zadnjih desetletjih močno 
razmahnile. Ob načrtovani neželeni ali neustrezni prenovi ulic in trgov so bili organizirani množični protesti proti tovrstnim spremembam. Oblasti so se kljub temu redko odpovedale svojim projektom in so jih uspešno izpeljale. Nevladne organizacije so postale pomemben akter v sodelovanju javnosti, saj si prizadevajo vzpostaviti komunikacijo med političnimi akterji in javnostjo ter javnost vključiti v načrtovalski proces, da lahko izrazi svoja mnenja. Kljub nedvomno opaznejši vlogi civilne družbe Bežovan in Zrinščak (2006: 8) opozarjata, da je še vedno bolj reaktivna kot proaktivna, njene organizacije pa še vedno ne prispevajo specifičnega družbenega kapitala. Državljani imajo v okviru zakona nekatere možnosti, da predstavijo svoje predloge ali se pritožijo, in sicer lahko to storijo na občnih zborih. Odločitve, sprejete na teh zborih, so zavezujoče za lokalni ali okrajni svet, ne pa tudi za mestno skupščino (internet 2; členi 127-129). Navedeno je primer izključevanja prebivalcev iz odločanja in neupoštevanja njihovih mnenj v sklepnih fazah projektov, kar je podobno že omenjenemu instrumentalnemu pristopu, povezanemu z zmanjšano vlogo države in javnosti, ki je zato zelo pasivna. To se ujema tudi z nižjimi ravnmi sodelovanja javnosti na lestvici Arnsteinove (obveščanje, terapija in manipulacija). Eden izmed razlogov za to je lahko tudi, da prebivalci ne želijo biti vključeni v sodelovanje. Trenutno nekateri vidiki lokalne samouprave niso preveč spodbudni za prebivalce, ki se zavedajo svojih omejitev, nepomembnosti in postranskosti pri reševanju vsakdanjih težav skupnosti (Rešetar, 2009; Toš idr., 2012). Pri prostorskih preureditvah v tovrstnem enosmernem procesu je pogosta manipulacija, katere namen je okrepiti politično moč vodilnih struktur, zlasti vlogo župana in njegovega kabineta. Zanimivo je, da daje župan v javnosti vtis, da želi izboljšati kakovost življenja prebivalcev ter prisluhniti njihovim željam in potrebam, vendar zaradi sodelovanja z investitorji tega nikoli ne uresniči. Pri odločanju sodelujejo samo vodilne elite kot izbrani in vplivnejši sloj prebivalstva, kar vodi v elitno prevlado, ki zavira sodelovanje (Silver idr., 2010) ali vključenost večine prebivalstva.

\subsection{Sodelovanje javnosti v Ljubljani}

Uradna podlaga za sodelovanje javnosti pri okoljskem in prostorskem razvoju je Aarhuška konvencija (ZN/ECE, 1998), ki jo je Slovenija ratificirala leta 2004 ob pridružitvi Evropski uniji in jo postopno vključila $\mathrm{v}$ nacionalno zakonodajo, med drugim tudi v ZUrep-2. Načelo sodelovanja javnosti je $\mathrm{v}$ tem zakonu opredeljeno v 11. členu, ki določa, da morajo pristojni organi omogočiti zgodnje in učinkovito sodelovanje javnosti pri odločanju in sprejemanju prostorskih aktov ter pri zadevah urejanja prostora na splošno. Vsakdo ima pravico do vpogleda $\mathrm{v}$ prostorske akte in vso dokumentacijo, povezano $\mathrm{z}$ njihovo pripravo in sprejemanjem $\mathrm{v}$ skladu $\mathrm{s}$ tem zakonom in zakonom, ki ureja dostop do informacij javnega značaja. Vsakdo ima pravico dajati pobude, predloge, pripombe in mnenja na prostorske akte, do katerih se mora organ v postopku njihove priprave opredeliti in o tem obvestiti javnost. ZUrep-2 poleg tega predvideva poseben pravni status za nevladne organizacije, ki imajo aktiven status delovanja v javnem interesu na področju prostora, varstva okolja, ohranjanja narave ali varstva kulturne dediščine - njihov pravni interes na tem področju se šteje za izkazanega po zakonu. V 85. členu zakon določa, da je treba zagotoviti načrt sodelovanja javnosti pri pripravi prostorske dokumentacije, v 111. členu pa dodatno opredeljuje postopke za pripravo občinskih prostorskih načrtov ter predvideva izvedbo javnih posvetov, delavnic ali drugih načinov sodelovanja z javnostjo.

Kvac idr. (2015) opozarjajo, da je ena izmed glavnih ovir pri izvedbi sodelovalnih praks pasivno ali zgolj formalno uresničevanje zakonodajnih zahtev po sodelovalnih pristopih. Načrtovalski organi le redko upoštevajo pripombe in zamisli, ki jih javnost poda na javnih posvetovanjih, ne glede na to, kako dobro so utemeljene. Poleg tega postopki, ki jih opredeljuje zakon, ne zagotavljajo popolne podpore tovrstnim praksam; na primer ustanove lahko temeljito spremenijo prvotni načrt, ki je bil predmet javne razprave, končni načrt pa kljub pomembnim spremembam ni znova poslan $\mathrm{v}$ javno obravnavo. Zato poskušajo civilne pobude in nevladne organizacije uveljavljati tovrstne prakse na področju urejanja prostora s svojimi aktivnostmi, ki temeljijo na pristopu od spodaj navzgor (Nikšič idr., 2018). Poleg tovrstnih konkretnih aktivnosti se osredotočajo tudi na krepitev zmogljivosti javnosti, pri čemer izdajajo priporočila in navodila, ki lokalne prostorske organe spodbujajo $\mathrm{k}$ vključevanju javnosti v urejanje prostora, ob tem pa prebivalce usmerjajo, kako naj v teh zapletenih postopkih proaktivno sodelujejo in izrazijo svoje mnenje. Tovrstni dokumenti so pomembno mehko orodje, ki deležnike vodi skozi zapletene postopke in jim pokaže najprimernejša orodja in tehnike, ki jih lahko uporabijo.

Ko je pred dvajsetimi leti Mestna občina Ljubljana (2002) začela pripravljati novo prostorsko zasnovo mesta (prvo v postsocialističnem obdobju), je takratna mestna uprava razumela potrebo po pravem sodelovalnem pristopu, saj je želela oblikovati dobro premišljeno zasnovo, ki bi izražala želje najrazličnejših lokalnih deležnikov. Poleg zakonsko zavezujočih postopkov, ki so zahtevali, da se v načrtovanje vključi širša javnost, so bili izvedeni zelo številne strokovne študije, posvetovanja z raznimi interesnimi skupinami in tematske delavnice za prebivalce. Na podlagi navedenega so bili izdani številne publikacije in dokumenti, ki so izražali želje in zamisli širše javnosti, ki brez obsežne uporabe sodelovalnih orodij ne bi bile razkrite. Rezultati obsežnih sodelovalnih aktivnosti pa niso bili vedno vključeni v pravno zavezujočo prostorsko dokumentacijo, zato so bile navedene aktivnosti ob spremembi političnih razmer $\mathrm{v}$ mestu le delno uspešne. Leta 2006 je vodenje mesta prevzela 
nova mestna uprava s svojo razvojno vizijo, ki je temeljila na pristopu od zgoraj navzdol in se ni vedno skladala s cilji, opredeljenimi v začetni (sodelovalni) fazi (Koželj, 2009). Trenutna mestna uprava izvaja vse zakonsko zavezujoče faze javnega posvetovanja (npr. ob vsaki spremembi in dopolnitvi prostorskega načrta), vendar sodelovanje javnosti v najbolj neposredni obliki še vedno poteka na ravni aktivnosti civilne družbe. Po različnih ljubljanskih soseskah se ljudje organizirajo v skupine, katerih aktivnosti večinoma temeljijo na prostovoljnem delu in osebni zavzetosti, saj prejmejo le malo javne finančne podpore (Nikšič, 2018; internet 3). Dve tovrstni pobudi sta predstavljeni v nadaljevanju.

\section{Metode}

Članek temelji na izsledkih dvostranskega raziskovalnega projekta z naslovom Urbana revitalizacija mestnega središča na primeru Ljubljane: primerjava z mestnim središčem Zagreba (2018-2019). Pri proučevanju urbane revitalizacije v obeh mestih je bila uporabljena primerjalna metoda, na podlagi katere so bile ugotovljene podobnosti, skupne značilnosti in razlike (Žugaj idr., 2006). Terenska raziskava, ki je v letih 2018 in 2019 potekala v Zagrebu in Ljubljani, je temeljila na štirih študijah primera (po dve v vsakem mestu). Kot izpostavljajo Burnham idr. (2006), primerjalna metoda omogoča, da se informacije umestijo v kontekst, ki se proučuje in interpretira, kar je še zlasti pomembno ob pridobljenih novih informacijah, ki jih je treba povezati s prejšnjimi izsledki. Projekt je poleg tega vključeval poskus primerjave dveh podobnih držav iz iste regije (Dogan, 2009: 23), v tem primeru Hrvaške in Slovenije. Primerjalna metoda v družboslovju omogoča objektivnejše razumevanje proučevanega družbenega pojava, njegovo umestitev in klasifikacijo ter oblikovanje sklepov (preverjanje hipoteze) in napovedi (Hague idr., 2001; Reason in Bradbury, 2001). Kot navajata Denzin in Linkoln (1994), študije primera omogočajo podrobnejše razumevanje družbenih procesov na podlagi analize enega ali več primerov. So empirične raziskave sodobnih pojavov v njihovem realnem kontekstu, ki temeljijo na različnih virih dokazov. Ker se osredotočajo na konkretne primere, omogočajo poglobljeno razumevanje izbranega pojava glede na njegovo prostorsko ali drugo umeščnost (Ritchie in Lewis, 2003; Yin, 2003).

Cilj raziskave je bil na podlagi izbranih primerov predstaviti razlike $\mathrm{v}$ procesu sodelovanja javnosti in s primerjalno metodo opredeliti konkretne in problematične vidike vzpostavljanja in izvajanja tega procesa. Primerjava je temeljila na naslednjih raziskovalnih vprašanjih: kako so se prebivalci in civilni sektor odzvali in aktivirali, ali je bil na podlagi posredovanja ali odziva civilne družbe začetni projektni načrt spremenjen ter kateri model sodelovanja javnosti po Arnsteinovi in drugih avtorjih (npr. instrumentalni, transformativni ali mešani) je bil uporabljen v primeru Ljubljane in kateri v primeru Zagreba. Pri primerjalni analizi je bil vsak primer proučen posebej glede na časovni potek dogodkov od začetka vsakega projekta ter vključitve in aktivacije javnosti do končnega rezultata ( $\mathrm{tj}$. reakcije ali v nekaterih primerih akcije civilnih akterjev). Najprej sta se med seboj primerjala oba primera v vsaki državi, nato pa še vsi štirje primeri skupaj, s poudarkom na vlogi civilnih akterjev v vsakem primeru, na podlagi česar so bili določeni modeli sodelovanja za vsako državo. Omenjeni štiri primeri (park Tabor in soseska BS 7 v Ljubljani ter Meštrovićev paviljon in park Savica v Zagrebu) so bili izbrani zato, ker dobro ponazarjajo proces sodelovanja različnih zainteresiranih strani (strokovnih, političnih in civilnih krogov) $v$ obeh mestih. So najrazločnejši primeri razlik med obema državama $\mathrm{z}$ vidika pristopa $\mathrm{k}$ prostorskemu načrtovanju (tj. od spodaj navzgor proti od zgoraj navzdol). Modeli, uporabljeni v obeh mestih, so povezani z že omenjenimi hipotezami o instrumentalnem, transformativnem in mešanem pristopu (Anokye, 2013) k sodelovanju javnosti, na podlagi katerih lahko razvrstimo analizirane primere.

\section{Rezultati}

\subsection{Prvi primer sodelovanja od spodaj navzgor: park Tabor v Ljubljani}

Park Tabor je lokalni park v vzhodnem delu Ljubljane, 10 minut hoje od Prešernovega trga. Na tem odprtem javnem prostoru, ki meri približno 1,2 ha, ima svoje površine tudi Športno društvo Tabor. Čeprav je zeleno središče širše soseske, je bil dolga leta zanemarjen in zapuščen, ljudje pa se v njem ponoči niso radi zadrževali, saj je bil neurejen in slabo osvetljen. Leta 2010 se je kulturno društvo Prostorož, ki se zavzema za izboljšanje javnega mestnega prostora in večjo vključenost javnosti, odločilo izkoristiti njegov potencial (internet 3). Eden izmed njegovih ciljev je bil spodbuditi lokalne prebivalce, da aktivno sodelujejo pri načrtovanju in izvedbi revitalizacije parka, ki je temeljila na uporabi minimalnih finančnih sredstev in manjših prostorskih izboljšavah, ki bi ustvarile priložnosti za druženje, igro in rekreacijo na prostem v prijetnem okolju. $\mathrm{Na}$ podlagi raziskave potenciala in težav območja (Cerar in Peterlin, 2010) ter številnih delavnic za spodbujanje sodelovanja je nastal program raznih aktivnosti, ki se je izvajal med letoma 2010 in 2014. Cilji aktivnosti so bili manjše prostorske izboljšave, $s$ katerimi bi prostor postal prijetnejši, sprememba prometnega režima in dajanje prednosti pešcem in kolesarjem ter ustvarjanje priložnosti za druženje lokalnih prebivalcev in obiskovalcev. Društvo Prostorož je usklajevalo aktivnosti organizacij, ki so v parku prostovoljno prirejale dogodke, zasnovalo urbano opremo parka in načrtovalo spremembe prometnega režima. 


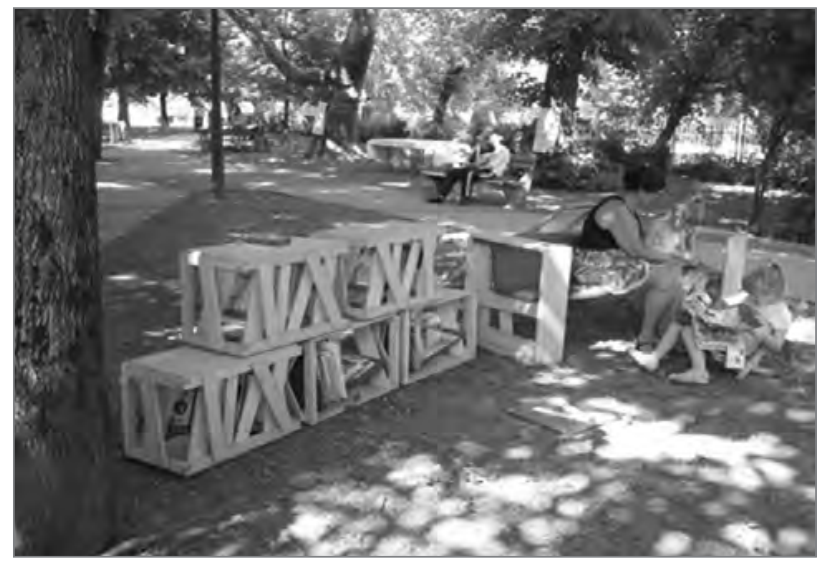

Slika 2: Park Tabor maja 2011: razne aktivnosti v parku (foto: Matej Nikšič)

Čeprav je revitalizacija parka Tabor (slika 2) značilen primer pristopa od spodaj navzgor, je projekt od mestne občine prejel tudi nekaj finančne podpore, kar je kulturnemu društvu omogočilo vsaj koordinacijo aktivnosti. Oddelki mestne uprave so bili pripravljeni pomagati in hkrati dovolj prilagodljivi, da so izdali potrebna dovoljenja. Sodelovanje med Prostorožem in oddelki mestne uprave je lahko zgled za podobne sodelovalne prakse v drugih delih mesta. Navedeno bi bil pomemben korak $\mathrm{k}$ revitalizaciji podobnih predmestnih javnih prostorov brez večjih finančnih vložkov (Bugarič, 2018). Med projektom so vsi vpleteni dobili boljši vpogled $\mathrm{v}$ organizacijo in mehanizme delovanja oddelkov mestne uprave, hkrati pa so ugotovili, da je $z$ vidika sodelovanja javnosti še veliko možnosti za izboljšave. Ko so pobudniki posameznih projektov svoje predloge izrazili $\mathrm{v}$ javnosti, ne glede na to, kako dobronamerni so bili, so bili pogosto razumljeni kot kritika mestne uprave, zaradi česar so jim umaknili podporo pri projektu in nekaterih aktivnostih (Human Cities Archives, 2017).

\subsubsection{Soseska BS 7 v Ljubljani}

Drug zanimiv primer, iz katerega se lahko veliko naučimo, je soseska BS $7 \mathrm{v}$ severnem delu Ljubljane, ki je v javnosti poznana tudi pod imenom Ruski car. Je ena največjih stanovanjskih sosesk v slovenski prestolnici, zgrajena $\mathrm{v}$ sedemdesetih letih 20. stoletja, z velikim osrednjim trgom, imenovanim Bratovševa ploščad. V socialističnem obdobju je bila ploščad prostor druženja, danes pa je to območje dokaj neizkoriščeno, saj ga ljudje večinoma uporabljajo samo za prehajanje z ene na drugo stran soseske. Zaradi dotrajanosti gradbenih materialov in nezadostnega vzdrževanja v zadnjih desetletjih je v slabem stanju, a ploščad do zdaj še ni bila prenovljena, predvsem zaradi neurejenega lastništva (poleg tega, da je osrednji odprt javni prostor v soseski, so tam tudi zasebne podzemne garaže). Skupina lokalnih prebivalcev je v okviru pobude Skupaj na

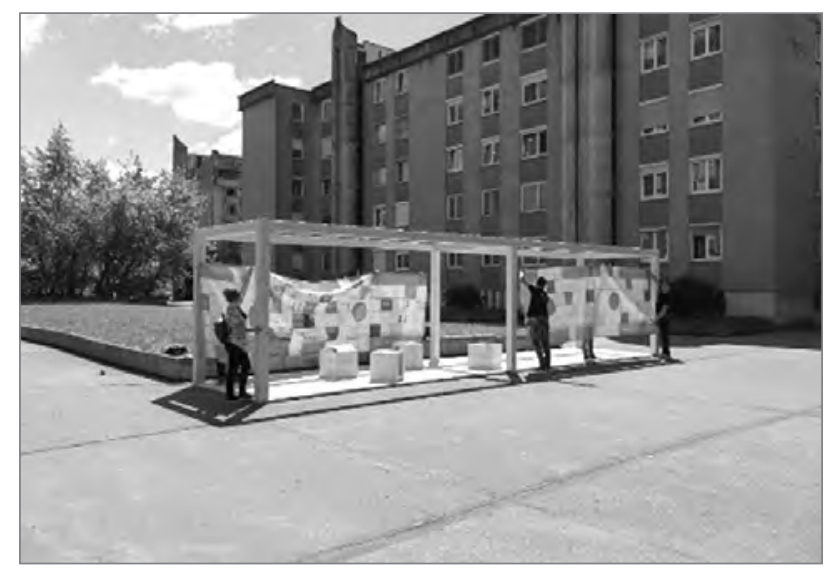

Slika 3: Sodelovalne aktivnosti na premalo izkoriščenem javnem prostoru v soseski BS 7 (foto: Tomaž Zupan)

ploščad (slika 3) zato začela izvajati nekatere nove aktivnosti, da bi pokazala, da ima območje velik potencial, in posledično vse lastnike (tj. lastnike podzemnih zasebnih garaž, upravnike bližnjih stanovanjskih blokov in mestno občino) spodbudila, da privolijo $\mathrm{v}$ prenovo ploščadi in zanjo zagotovijo finančna sredstva. Vsako leto pobuda prostovoljno organizira razne aktivnosti za lokalne prebivalce (in skupaj z njimi), katerih namen je oživiti sosesko (npr. ulični kino, zelenjavne tržnice in delavnice izdelave uličnega pohištva). Območje in sodelovanje tamkajšnjih prebivalcev sta pritegnila mednarodno pozornost ekipe projekta Humana mesta (Human Cities) v okviru programa Evropske unije Ustvarjalna Evropa (Franc idr. 2018), katerega cilj je okrepiti sodelovalne aktivnosti lokalnih prebivalcev z eksperimentalno uporabo raznih sodelovalnih orodij. Med letoma 2014 in 2018 so bili organizirani številni dogodki in aktivnosti, kot so vodeni sprehodi po soseski, okrogle mize, pikniki, risarske delavnice in delavnice izdelovanja maket, intervjuji, spletni fotografski natečaji in ulične razstave, da bi lokalne prebivalce spodbudili k druženju na ploščadi in $\mathrm{k}$ temu, da združijo moči in se skupaj odločijo, kako naj bi potekala njena temeljita prenova (Nikšič idr., 2018). Tudi ko je mestna uprava končno prepoznala pomen projekta in zanj ponudila finančno pomoč, je prizadevanja za prenovo zaviralo dejstvo, da se lokalna skupnost ni mogla sporazumeti glede stroškov projekta in prihodnje podobe ploščadi. Primer kaže, da lahko kljub široki podpori (stanovalcev, občine ter domačih in mednarodnih strokovnjakov) nesposobnost deležnikov, da se uskladijo, prepreči še tako dobronamerna sodelovalna prizadevanja. Kljub temu so tovrstne aktivnosti pomembne za krepitev zmogljivosti lokalnih prebivalcev, da sodelujejo pri urbani prenovi, ki se lahko začne šele, ko se glavni akterji sporazumejo glede pravične razdelitve projektnih stroškov. 


\subsection{Pristop od zgoraj navzdol ali reakcionistični aktivistični pristop $\mathrm{k}$ sodelovanju javnosti v Zagrebu: Meštrovićev paviljon}

Prenova Meštrovićevega paviljona (slika 4) sredi Trga žrtev fašizma v središču Zagreba je bila prva faza projekta z naslovom Center odličnosti za spodbujanje pešačenja. Paviljon je primer kulturnega in umetniškega spomenika ter priljubljenega javnega prostora, zaradi česar so prebivalci tudi budno spremljali njegovo prenovo. Študija primera, izvedena med letoma 2018 in 2019, je pokazala, da so se prebivalci na prenovo negativno odzvali in so jo poskušali ustaviti. Povsem na začetku je bilo okoli paviljona odstranjeno vse rastlinje, da bi lahko začeli načrtovano prenovo. Največji protest lokalnih in drugih prebivalcev je sledil potem, ko so izvajalci posekali magnolijo, zaradi česar je območje postalo golo in sterilno. Izvedli so kampanjo Vrnite magnolijo, ta pobuda pa je trajala šest mesecev. Celoten projekt je bil slabo predstavljen javnosti, zahtevani postopki pa niso bili izvedeni ali so jih zaobšli, poleg tega mnenja strokovnjakov, ki so poskušali vplivati na izvedbo projekta, niso bila upoštevana. Civilna pobuda je zahtevala zaustavitev del, javno posvetovanje, zaščito rastlinja, vrnitev magnolije in konstruktivnejšo razpravo pred dokončanjem projekta. Svoje prošnje in pozive je poslala pristojnim mestnim in državnim ustanovam. Kljub vsem aktivnostim in čedalje večjemu odporu raznih civilnih pobud od pristojnih ni bilo odziva in prva faza projekta je bila uspešno dokončana.

Med načrtovanjem so bili predvideni drenaža zelenih površin, zamenjava poškodovanega stopnišča okrog paviljona, položitev novih granitnih tlakovcev in kamnitih robnikov ter namestitev novih klopi, košev za smeti in stojal za kolesa. Brez javnega natečaja in posvetovanja pa se je zdelo, da je bil projekt plod županovega avtokratskega vodenja in manipulacije, ki sta skupnosti in strokovnjakom preprečevala, da bi sodelovali pri odločanju. Poleg tega sta bila brez posebnega razmisleka spremenjena zaščiteni kulturni spomenik in njegova zgodovinska identiteta. Kljub vsemu se je iz opisanega projekta urbane prenove na koncu vendarle izcimilo nekaj dobrega. Pobuda Vrnite magnolijo je dosegla, da je mestna uprava obljubila, da ne bo nikoli več stvari urejala tako, kot jih je na navedenem trgu (Svirčić Gotovac in Zlatar Gamberožić, 2020). Opisani primer jasno kaže, da so pri krčenju javnih in zelenih površin v Zagrebu nevladne organizacije postale edini posrednik med prebivalci in mestno upravo ter edini akter, ki se odziva na samovoljne ukrepe mestne uprave.

\subsubsection{Park Savica v Zagrebu}

V primeru parka Savica (2013-2018) je bila poglavitna gradnja cerkve v mestnem parku. Lokalna župnija je oddala prošnjo za izdajo lokacijskega dovoljenja, o čemer pa ni obvestila

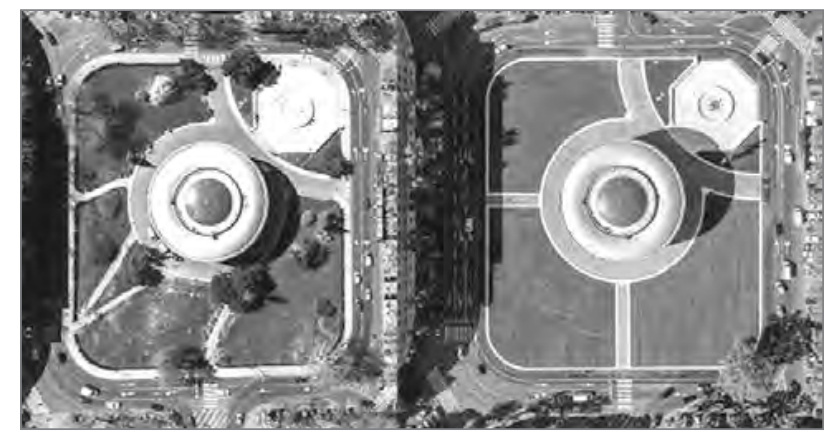

Slika 4: Meštrovićev paviljon pred prenovo in po njej v letih 2017 in 2018 (vir: Dobrić, 2018)

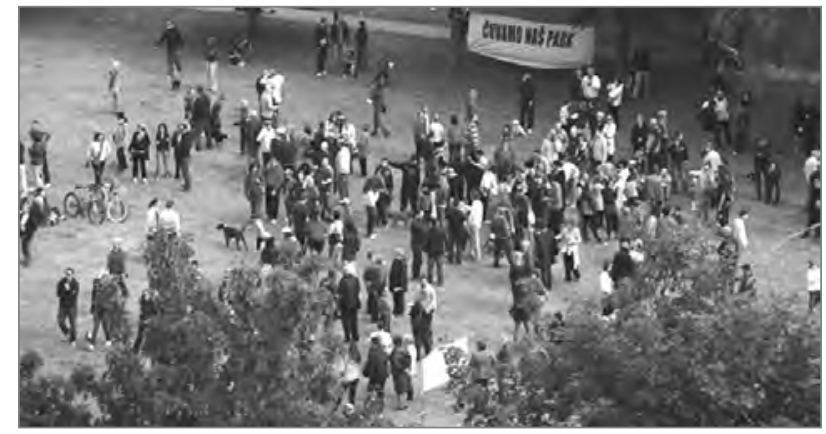

Slika 5: Protest proti gradnji cerkve v parku Savica leta 2017 (vir: HINA, 2016)

nobenega od lastnikov sosednjih parcel. V kataster je bila nepojasnjeno vnesena neobstoječa cesta med načrtovanim gradbiščem in sosednjo stavbo. Lokalni prebivalci so $s$ tem izgubili pravico do pritožbe, zato so sprožili kampanjo Varujmo naš park (slika 5), ta kampanja je trajala pet let. Organizirali so jo predvsem zaradi nepreglednih razpisnih postopkov in ker bi se zaradi projekta skrčila površina parka. Cerkev bi zavzemala $1.600 \mathrm{~m}^{2}$, kar je skoraj tretjina skupne površine parka. Ljudje, ki so se pridružili pobudi, so stalno poudarjali, da ne nasprotujejo gradnji cerkve, ampak izbrani lokaciji gradnje. Prebivalci, ki so pomagali zbirati podpise v podporo pobudi, so se poimenovali » prebivalci, ki smo za gradnjo cerkve, a ne v našem parku «. V skladu z vsemi postopki so poslali dopise pristojnim mestnim službam in županu. Združenji hrvaških arhitektov in krajinskih arhitektov sta podprli prebivalce in projektu nasprotovali. Naposled je ministrstvo za gradbeništvo in prostorsko ureditev razveljavilo dovoljenje, ki ga je leta 2016 izdala mestna občina Zagreb, med drugim zaradi velikosti projekta, ki ni bila v skladu z generalnim urbanističnim planom, in ker niso bili izvedeni ustrezni postopki javnega naročanja.

Primera Meštrovićevega paviljona in parka Savica sta podobna $z$ vidika njunih začetnih faz in odziva prebivalcev. Razlikujeta pa se v poznejši fazi, ko je bilo v primeru parka po večletnih prizadevanjih civilne družbe lokacijsko dovoljenje razveljavljeno. Oba primera dokazujeta, da lahko ob podpori strokovnjakov civilne pobude zaustavijo samovoljno ravnanje politike. 
Nista ravno zgled za to, kako naj bi civilna družba sodelovala pri odločanju, ponazarjata pa, kako se lahko javnost ozavešča in spodbudi $\mathrm{k}$ temu, da postane aktivna.

\section{Razprava}

Primerjalna analiza Meštrovićevega paviljona in parka Savica v Zagrebu je pokazala, da je bilo obema projektoma skupno dvoje: neupoštevanje mnenja javnosti in strokovnjakov ter vztrajno prizadevanje mestne uprave, da izpelje prvotna načrta kljub številnim nejasnim ali nepopolnim pravnim postopkom. Prebivalci so projektoma nasprotovali tako, da so izvedli bolj ali manj uspešne pobude. Primera iz Ljubljane izpostavljata pomen aktivnega državljanstva, pri čemer proaktivni prebivalci lahko prispevajo in želijo prispevati k drugačnemu dojemanju in preoblikovanju svojega bivalnega okolja. Po drugi strani pa jasno kažeta nestabilnost sodelovalnih praks in njihovo odvisnost od politične in finančne podpore. Dokler je navedena podpora zagotovljena, je večja verjetnost, da bo sodelovanje med akterji ali organizacijami, ki delujejo po pristopu od spodaj navzgor, in tistimi, ki delujejo po pristopu od zgoraj navzdol, privedla do tega, da bo rezultat najboljši za vse. Da bi lahko to dosegli, so poleg pravno zavezujočih podlag za sodelovanje javnosti potrebni zaupanje, sposobnost sodelovanja in dialog med vsemi pomembnimi partnerji. V primeru parka Tabor se je močno pokazalo plodno sodelovanje med lokalnimi akterji, v primeru soseske BS 7 pa se je izkazalo, da ima lahko sodelovalni pristop omejen vpliv, če je med akterji preveč trenj.

Kot je razvidno iz primerov v Ljubljani in Zagrebu, sodelovanje javnosti pri urbanističnem načrtovanju ter prenovi in zaščiti javnih prostorov še vedno ostaja razmeroma šibko. Podobno je tudi v drugih južnoevropskih mestih zadovoljstvo prebivalcev z ulicami ali stavbami nizko (Emerson in Smiley, 2018: 166), kar je lahko posledica šibkega sodelovanja javnosti pri urejanju prostora in njenega manjšega vpliva na javne prostore. V Zagrebu je vključenost javnosti omejena na proteste proti posameznim urbanističnim projektom in jo lahko opišemo kot primer reakcionističnega aktivizma, ki se lahko pogosto spremeni v pasivno sprejemanje obstoječega stanja. V Ljubljani lokalne skupnosti vzpostavljajo veliko bolj enakovrednejša partnerstva z lokalnimi oblastmi, ko se odloča o njihovem vsakdanjem življenju in okolju. Poleg tega vsi vpleteni akterji kažejo močno predanost svojim nalogam. Premislek o vlogi in vplivu lokalne skupnosti je ključen v urbanizmu postsocialističnih držav (Hlaváček idr., 2016). Sodelovanje javnosti je treba okrepiti, da so lahko prebivalci v celoti vključeni v odločanje o svojem ožjem bivalnem okolju.

\section{Sklep}

V primerjavi s primeroma iz Zagreba primera iz Ljubljane kažeta višjo raven sodelovanja javnosti, poleg tega je izrazito še, da je skupnost bolj vključena v vodenje načrtovanja (Svirčić Gotovac in Kerbler, 2019). Navedeno še zlasti velja za park Tabor, kjer so civilne pobude in lokalni prebivalci v sodelovanju z mestno upravo organizirali ulične prireditve in park spremenili $\mathrm{v}$ prijeten prostor druženja. Poleg tega so v Ljubljani aktivnosti civilne družbe bolj proaktivne kot $\mathrm{v}$ Zagrebu, kjer se večinoma reaktivne. Namesto protestov proti prostorskim posegom, vsiljenim od zgoraj, se civilne pobude v Ljubljani večinoma osredotočajo na izboljšanje potenciala posameznih mestnih okolij in krepitev sodelovanja med deležniki. Ljubljana torej kaže premik od postsocialističnega enosmernega instrumentalnega modela $\mathrm{k}$ transformativnemu pristopu, Zagreb pa ostaja pri instrumentalnem pristopu. Pri parku Savica v Zagrebu so opazne tudi značilnosti mešanega modela, saj so prebivalci zaustavili gradnjo cerkve ter zahtevali večjo vključenost $\mathrm{v}$ odločanje in upoštevanje njihovih potreb (kar spada $\mathrm{k}$ transformativnemu pristopu). Ker proces vseeno ni bil dvosmeren, gre v prvi vrsti za primer instrumentalnega sodelovanja javnosti.

Ljubljanski model lahko ob močnejši politični podpori postane še uspešnejši. Trenutno je politična podpora dokaj šibka in nestabilna, saj mestna uprava gibanja civilne družbe še vedno noče v celoti sprejeti kot enakovrednega partnerja pri odločanju in še vedno dojema njene dobronamerne kritike kot grožnjo. Podobna težava je opazna v Zagrebu, kjer ni resničnega sodelovanja javnosti, ampak je to samo v obliki odziva na že obstoječe razmere, komunikacija z mestno upravo pa je več kot očitno nezadostna. Hipoteza, da je za Ljubljano značilna višja raven sodelovanja javnosti pri zadevah, ki se nanašajo na kakovost življenja in okolja, kot za Zagreb, je bila tako potrjena. Še vedno pa je v obeh mestih veliko možnosti za izboljšave, predvsem zaradi nezmožnosti lokalnih akterjev (strokovnjakov, prebivalcev in oblasti), da se uskladijo in stopijo skupaj, kar z vidika sodelovanja javnosti ostaja velik izziv. Potrebni so spremembe pravnega okvira, večje ozaveščanje prebivalcev o njihovih pravicah in odprtost za nove prakse od spodaj navzgor v skladu s priporočili EU, na podlagi česar bi sodelovanje javnosti postalo in ostalo stalnica pri urejanju prostora, urbanistična politika pa bi upoštevala javne potrebe.

Anđelina Svirčić Gotovac, Inštitut za družbene raziskave, Zagreb, Hrvaška

E-naslov: angelinasg@gmail.com

Jelena Zlatar Gamberožić, Inštitut za družbene raziskave, Zagreb, Hrvaška

E-naslov: zlatar.jel@gmail.com 
Matej Nikšič, Urbanistični inštitut Republike Slovenije, Ljubljana, Slovenija E-naslov: matej.niksic@uirs.si

\section{Zahvala}

V članku so predstavljeni izsledki dvostranskega raziskovalnega projekta z naslovom Urbana revitalizacija mestnega središča na primeru Ljubljane: primerjava z mestnim središčem Zagreba, ki sta ga izvajala Inštitut za družbene raziskave $v$ Zagrebu in Urbanistični inštitut Republike Slovenije. Projekt sta financirala hrvaško ministrstvo za znanost in izobraževanje ter Javna agencija za raziskovalno dejavnost Republike Slovenije (ARRS). Priprava prispevka je bila delno podprta $\mathrm{s}$ sredstvi ARRS v okviru raziskovalnega programa Prostorsko načrtovanje P5-0100.

\section{Viri in literatura}

Anokye, N. A. (2013): Stakeholder participation in water resources management: The case of Densu Basin in Ghana. Doktorska disertacija. Amsterdam, Vrije Universiteit.

Arnstein, S. R. (1969): A ladder of citizen participation. Journal of the American Institute of Planners, 35(4), str. 216-224.

DOI: $10.1080 / 01944366908977225$

Bertaud, A., in Renaud, B. (1997): Socialist cities without land markets. Journal of Urban Economics, 41(1), str. 137-151.

DOI: 10.1006/juec.1996.1097

Beyea, W., Geith, C., in McKeown, C. (2008): Place making through participatory planning. Chapter 4. V: Foth, M. (ur.): Handbook of research on urban informatics: The practice and promise of the real-time city, str. 55-68. Hershey, PA, Information Science Reference.

DOI: $10.1093 / \mathrm{cdj} / 35.1 .41$

Bežovan, G., in Zrinščak, S. (2006): Is civil society in Croatia becoming a force for social change? Croatian Journal of Social Policy, 14(1), str. 1-27.

Botes, L., in van Rensburg, D. (2000): Community participation in development: Nine plagues and twelve commandments. Community Development Journal, 35, str. 41-58. DOI: 10.1093/cdj/35.1.41

Bugarič, B. (2018): Urban acupuncture treatment: Implementing communication tools with youth in Ljubljana suburbs. Urbani izziv, 29(posebna izdaja), str. 95-108.

DOI: 10.5379/urbani-izziv-en-2018-29-supplement-006

Burnham, P., Gilland, K., Grant, W., in Layton-Henry, Z. (2008): Research methods in politics. London, Macmillan.

DOI: 10.1007/978-0-230-36556-8

Burton, R., Dickman, W., in Fisher, J. C. (1967): Toward a system of social planning in Yugoslavia. Papers of the Regional Science Association, 18, str. 75-86. DOI: 10.1007/BF01940313

Cerar, A., in Peterlin, M. (ur.) (2010): Revitalizacija parka Tabor: urejanje parka z vključevanjem lokalne skupnosti. Ljubljana, IPOP.

Čaldarović, O., in Kritovac, F. (1987): Stambene potrebe i njihovo zadovoljavanje. V: Bežovan, G., in Kuzmanović, M. (ur.): Stambena politika i stambene potrebe, str. 63-80. Zagreb, Radničke novine.

Denzin, N. K., in Linkoln, Y. S. (ur.) (1994): Handbook of qualitative research. Thousand Oaks, Kalifornija, Sage Publications.
Dimitrovska Andrews, K., Mihelič, B., in Stanič, I. (2007): The post-socialist urban restructuring of Ljubljana: Strengthening identity. V: Stanilov, K. (ur.): The post-socialist city: Urban form and space transformations in Central and Eastern Europe after socialism, str. 427-447. Cincinnati, $\mathrm{OH}$ Springer. DOI: 10.1007/978-1-4020-6053-3_21

Dobrić Žaja, S. (2018): Kreće li Bandićev napad na Branimirac i Krešimirac? Dostopno na: https://www.h-alter.org/vijesti/ krece-li-bandicev-napad-na-branimirac-i-kresimirac (sneto 1. 9. 2020).

Dogan, M. (2009): Strategies in comparative sociology. V: Sasaki, M. (ur.): New frontiers in comparative sociology. International studies in sociology and social anthropology, str. 13-45. Leiden, Brill.

Emerson, M. O., in Smiley, K. T. (2018): Across cities. V: Emerson, O., in Smiley, K. T. (ur.): Market cities, people cities. The shape of our urban future, str. 162-177. New York, New York University Press. DOI: $10.18574 /$ nyu/9781479856794.003.0008

ESPON (2018): COMPASS - Comparative Analysis of Territorial Governance and Spatial Planning Systems in Europe. Luksemburg, ESPON.

Franc, J., Peyricot, O., Ermacora, T., in van Hasselt, F. (ur.) (2018): Human cities challenging the city scale: journeys in people-centred design. Basel, Birkhäuser Verlag.

Golubchikov, O. (2004): Urban planning in Russia: Towards the market. European Planning Studies, 12(2), str. 229-247. DOI: $10.1080 / 0965431042000183950$

Grad Zagreb (2016): Odluka o donošenju Generalnoga urbanističkog plana grada Zagreba (pročišćeni tekst). Dostopno na: https://www.zagreb. hr/odluka-o-donosenju-generalnoga-urbanistickog-plana/89158 (sneto 25. 2. 2021).

Häusserman, H., in Kapphan, A. (2004): Berlin: from divided into fragmented city. The Greek Review of Social Research, 113, str. 25-61. DOI: $10.12681 /$ grsr.9216

HINA (2016): Park na Savici: izdana lokacijska dozvola za gradnju crkve bl. Alojzija Stepinca. Dostopno na: https://www.nacional.hr/park-na-savici-izdana-lokacijska-dozvola-za-gradnju-crkve-bl-alojzija-stepinca/ (sneto 1. 9. 2020)

Hirt, A. S. (2012): Iron curtains gates, suburbs and privatization of space in the post-socialist city. Hoboken, NJ, John Wiley \& Sons. DOI: 10.1002/9781118295922

Hlaváček, P., Raška, P., in Balej, M. (2016): Regeneration projects in central and eastern European post-communist cities: Current trends and community needs. Habitat International, 56, str. 31-41.

DOI: 10.1016/j.habitatint.2016.04.001

Hordijk M., Miranda Sara L., Sutherland C., in Scott D. (2015): Participatory instruments and practices in urban governance. V: Gupta, J., Pfeffer, K., Verrest, H., in Ros-Tonen, M. (ur.): Geographies of Urban Governance, 26(1), str. 130-146. DOI: 10.1007/978-3-319-21272-2_7

Human Cities Archives (2017): Interviews with initiators of civil initiatives. Unpublished materials of the Human Cities Ljubljana project. Ljubljana, Urbanistični inštitut Republike Slovenije.

Internet 1: www.citizenshandbook.org (sneto 4. 10. 2020).

Internet 2: https://www.zagreb.hr/statut-grada-zagreba/110 (sneto 5. 9. 2020).

Internet 3: http://prostoroz.org/portfolio/items/park-tabor/ (sneto 1. 9. 2020).

Jaakson, R. (2000): Supra-national spatial planning of the Baltic Sea region and competing narratives for tourism. European Planning Studies, 8, str. 565-579. DOI: 10.1080/713666424 
Koželj, J. (2009): Poudarki in vizije dolgoročnega razvoja Ljubljane do leta 2025. AB Arhitektov bilten, 39(181/182), str. 4-6.

Kvac, B., Peterlin, M., in Vrbica, S. (2015): Dobre prakse vključevanja javnosti na področju varstva okolja in urejanja prostora. Ljubljana, PIC.

Mestna občina Ljubljana (2002): Prostorska zasnova 2002. Dostopno na: https://www.ljubljana.si/sl/moja-ljubljana/urbanizem/ o-zgodovini-urbanisticnega-nacrtovanja/prostorska-zasnova-2002/ (sneto 7. 9. 2020)

Nikšič, M. (2014): Access to quality open public space as an urban sustainability measure. V: Bokor, L., Munkacsy, B., in Nikšič, M. (ur.): Locality and (un)sustainable settlements, str. 284-303. Shrewsbury, Frugeo Geography Research Initiative.

Nikšič, M. (2018): Participatory revitalisation of urban public open space: Urban planners' skills needed for improvement of urban public spaces in participatory manner. V: Novaković, N., Grom, J. P., in Fikfak, A. (ur.): Realms of urban design: Mapping sustainability, str. 197-215. Delft TU Delft Open.

Nikšič, M., Goršič, N., in Tominc, B. (2018): Tools for participatory provision of urban public spaces: Human cities experience. V: Nikšič, M., Goršič, N., Tominc, B., Selloni, D, Galluzzo, L., Fassi, D., idr. (ur.): Human cities: Challenging the city scale 2014-2018: Investigation, str. 7-23. Saint-Etienne, Francija, Cite du Design.

Nikšič, M., in Sezer, C. (2017). Public space and urban justice. Built Environment, 43(2), str. 165-172. DOI: 10.2148/benv.43.2.165

Offe, C. (1997): Microaspects of democratic theory: What makes for the deliberative competence of citizens? V: Hadenius, A. (ur.): Democracy's Victory and Crisis, str. 81-104. Cambridge, Cambridge University Press. DOI: $10.1017 / C B O 9780511558832.005$

Patti, D., in Polyak, L. (ur.) (2017): Funding the cooperative city. Dunaj, Cooperative City Books.

Reason, P., in Bradbury, H. (ur.) (2001): Handbook of action research: Participative inquiry and practice. London, Sage.

Rešetar, V. (2009): Local committee: Representative of citizens or local political elites. Croatian Public Administration, 9(3), str. 773-796.

Richards, L., in Dalbey, M. (2006): Creating great places: The critical role of citizen participation. Community Development: The Journal of the Community Development Society, 37(4), str. 18-32.

DOI: $10.1080 / 15575330609490193$

Ritchie, J., in Lewis, J. (2003): Qualitative research practice. A guide for social science students and researchers. London, Sage Publications.

Silver, H., Scott, A., in Kazepov, Y. (2010): Participation in urban contention and deliberation. International Journal of Urban and Regional Research, 34(3), str. 453-477. DOI: 10.1111/j.1468-2427.2010.00963.x

Svirčić Gotovac, A., in Kerbler, B. (2019): From post-socialist to sustainable: The city of Ljubljana. Sustainability, 11(126), str. 1-16.

DOI: $10.3390 /$ su11247126

Svirčić Gotovac, A., in Zlatar Gamberožić, J. (2020): Defense of public spaces in the cases of "We are keeping our park" and "Bring back the magnolia" initiatives in Zagreb. Sociology and Space, 58(1), str. 5-31.

Sýkora, L., in Stanilov, K. (2014): The challenge of postsocialist suburbanization. V Stanilov, K., in Sýkora, L. (ur.): Confronting suburbanization: Urban decentralization in postsocialist central and eastern Europe, str. 1-33. Chichester, VB, John Wiley \& Sons, Ltd.

DOI: 10.1002/9781118295861.ch1

Toš, I. (ur.) (2012) Participacija u procesima razvoja izgrađene okoline: izvještaj o terenskom istraživanju. Zagreb, Filozofski fakultet Sveučilišta, Katedra za antropologiju.
ZN/ECE (1998): Konvencija o dostopu do informacij, udeležbi javnosti pri odločanju in dostopu do pravnega varstva v okoljskih zadevah. Aarhus, Ekonomska komisija Združenih narodov za Evropo.

Walzer, N. (2010): CDS at 40: The past leading to the future. Community Development. Journal of the Community Development Society, 41(4), str. 401-404. DOI: $10.1080 / 15575330.2010 .532680$

Yin, R. (2003): Case study research, design and methods. Thousand Oaks, Kalifornija, Sage.

Zakon o prostornom uređenju. Narodne novine, št. 153/13, 65/17, 114/18, 39/19, 98/19. Zagreb.

Zakon o urejanju prostora. Uradni list Republike Slovenije, št. 61/2017. Ljubljana.

Zlatar Gamberožić, J. (2019): Revitalization paths of urban centers: tentative observational comparison of two cities: Ljubljana and Zagreb. Družboslovne razprave, 35(90), str. 83-104.

Žugaj, M., Dumičić, K., in Dušak, V. (2006): Temelji znanstvenoistraživačkog rada: metodologija i metodika. Varaždin, TIVA. 